Cochrane Database of Systematic Reviews

\title{
Mannitol for acute stroke (Review)
}

Bereczki D, Liu M, Fernandes do Prado G, Fekete I

Bereczki D, Liu M, Fernandes do Prado G, Fekete I.

Mannitol for acute stroke.

Cochrane Database of Systematic Reviews 2007, Issue 3. Art. No.: CD001153.

DOI: 10.1002/14651858.CD001153.pub2.

www.cochranelibrary.com 
TABLE OF CONTENTS

HEADER 1

ABSTRACT

PLAIN LANGUAGE SUMMARY

BACKGROUND

OBJECTIVES

METHODS

RESULTS

DISCUSSION

AUTHORS' CONCLUSIONS

ACKNOWLEDGEMENTS

REFERENCES

CHARACTERISTICS OF STUDIES

DATA AND ANALYSES

Analysis 1.1. Comparison 1 Mannitol plus standard therapy versus standard therapy, Outcome 1 Death or disability.

Analysis 1.2. Comparison 1 Mannitol plus standard therapy versus standard therapy, Outcome 2 Case fatality.

Analysis 1.3. Comparison 1 Mannitol plus standard therapy versus standard therapy, Outcome 3 Clinical condition worsening.

Analysis 1.4. Comparison 1 Mannitol plus standard therapy versus standard therapy, Outcome 4 Clinical condition not improving.

WHAT'S NEW

HISTORY

CONTRIBUTIONS OF AUTHORS

DECLARATIONS OF INTEREST

SOURCES OF SUPPORT

INDEX TERMS 
[Intervention Review]

\section{Mannitol for acute stroke}

Dániel Bereczki¹, Ming Liu² ${ }^{2}$ Gilmar Fernandes do Prado³ , István Fekete 4

1Department of Neurology, Semmelweis University, Budapest, Hungary. ${ }^{2}$ Department of Neurology, West China Hospital, Sichuan University, Chengdu, China. ${ }^{3}$ Universidade Federal de São Paulo, São Paulo, Brazil. ${ }^{4}$ Department of Neurology, University of Debrecen, Health Science and Medical Center, Debrecen, Hungary

Contact address: Dániel Bereczki, Department of Neurology, Semmelweis University, Balassa u. 6., Budapest, H-1083, Hungary. bereczki@neur.sote.hu.

Editorial group: Cochrane Stroke Group

Publication status and date: Edited (no change to conclusions), published in Issue 1, 2009.

Citation: Bereczki D, Liu M, Fernandes do Prado G, Fekete I. Mannitol for acute stroke. Cochrane Database of Systematic Reviews 2007, Issue 3. Art. No.: CD001153. DOI: 10.1002/14651858.CD001153.pub2.

Copyright @ 2009 The Cochrane Collaboration. Published by John Wiley \& Sons, Ltd.

\section{A B S T R A C T}

\section{Background}

Mannitol is an osmotic agent and a free radical scavenger which might decrease oedema and tissue damage in stroke.

\section{Objectives}

To test whether treatment with mannitol reduces short and long-term case fatality and dependency after acute ischaemic stroke or intracerebral haemorrhage (ICH).

\section{Search methods}

We searched the Cochrane Stroke Group Trials Register (searched December 2006), MEDLINE (1966 to January 2007), the Chinese Stroke Trials Register (searched November 2006), the China Biological Medicine Database (searched December 2006) and the Latin-American database LILACS (1982 to December 2006). We also searched the database of Masters and PhD degree theses at Sao Paulo University (searched January 2007), and neurology and neurosurgery conference proceedings in Brazil from 1965 to 2006 . In an effort to identify further published, ongoing and unpublished studies we searched reference lists and contacted authors of published trials.

\section{Selection criteria}

We included randomised controlled trials comparing mannitol with placebo or open control in patients with acute ischaemic stroke or non-traumatic intracerebral haemorrhage.

\section{Data collection and analysis}

Two review authors independently selected trials, assessed quality, extracted data, and performed the data analysis.

\section{Main results}

Three small trials, involving 226 participants, were included. One trial included patients with presumed ischaemic stroke without computerised tomography (CT) verification, and the other two trials included patients with CT-verified ICH. Data on the primary outcome measure (death and dependency) were not available in any of the trials. Death and disability could be calculated in the larger ICH trial without differences between the mannitol and control groups. Case fatality was not reported in the trial of ischaemic stroke. Case fatality did not differ between the mannitol and control groups in the ICH trials. Adverse events were either not found or not reported. The change in clinical condition was reported in two trials, and the proportion of those with worsening or not improving condition did not differ significantly between mannitol-treated patients and controls. Based on these three trials neither beneficial nor harmful effects of mannitol could be proved. Although no statistically significant differences were found between the mannitol-treated and control groups, 
the confidence intervals for the treatment effect estimates were wide and included both clinically significant benefits and clinically significant harms as possibilities.

\section{Authors' conclusions}

There is currently not enough evidence to support the routine use of mannitol in acute stroke patients. Further trials are needed to confirm or refute whether mannitol is beneficial in acute stroke.

\section{PLAIN LANGUAGE SUMMARY}

\section{Mannitol for acute stroke}

Brain swelling (oedema) is a major cause of early death and long-term disability after stroke (a sudden catastrophe in the brain either because an artery to the brain blocks, or because an artery in or on the brain ruptures and bleeds). Mannitol solution is given into a vein to reduce the swelling. Increased (rebound) swelling in the brain can occur after the treatment is stopped. This review of three small trials, involving 226 participants, found that there was not enough evidence to decide if mannitol improves survival or prevents disability after stroke. The treatment can cause a number of adverse effects, but no serious adverse events were reported in the trials included in this review. More research is needed. 


\section{B A C K G R O U N D}

There is no specific medical therapy that can be recommended for routine use in patients with acute ischaemic stroke except for aspirin (CAST 1997; IST 1997). Thrombolysis with tissue plasminogen activator is recommended in selected patients (Adams 1996), but there is insufficient evidence to recommend the use of thrombolytic drugs in general to treat acute ischaemic stroke (Wardlaw 2003). Only a few randomised trials exist for nontraumatic intracerebral haemorrhage $(\mathrm{ICH})$. Most of these could not prove a beneficial effect of medical (Poungvarin 1987; Yu 1992) or surgical (Mendelow 2005; Prasad 1998) interventions. The application of the recombinant activated coagulation factor VII (rFVIIa) is promising: within four hours after the onset of intracerebral haemorrhage it was reported to limit the growth of the haematoma, to reduce mortality, and to improve functional outcomes at 90 days, despite a small increase in the frequency of thromboembolic adverse events (Mayer 2005).

Ischaemic stroke is associated with cytotoxic (intracellular) and vasogenic (extracellular, interstitial) oedema (Katzman 1977; Rabinstein 2006). Cytotoxic oedema develops in the first hours after the onset of ischaemic stroke and can be detected as a decrease in the apparent diffusion coefficient (ADC) of water. This reduction in $A D C$ lasts for three to four days, and then increases as vasogenic oedema develops (Schlaug 1997; Warach 1995). A decrease in ADC was also shown in acute haemorrhagic stroke (Ebisu 1997), but in contrast to ischaemic strokes, $A D C$ in haemorrhagic stroke remains decreased even 100 days after stroke onset. Continuous monitoring of intracranial pressure (ICP) shows that the pronounced brain oedema which develops during the fourth to the 14th day of an intracerebral haemorrhage could lead to an increase in ICP requiring treatment (Haass 1987).

Corticosteroids, although frequently used to treat cerebral oedema, did not increase survival after stroke (Qizilbash 2002). Osmotic diuretics are among the agents that are widely used in the treatment of cerebral oedema (James 1980; Reyes 1981; Schierhout 1998; Woster 1990). Glycerol is frequently used in stroke in several countries, although currently there is not enough evidence to evaluate glycerol treatment for people with acute ischaemic stroke (Righetti 2004).

Mannitol is thought to decrease ICP by decreasing overall water content of the brain and cerebrospinal fluid (CSF) volume, and by reducing blood volume due to vasoconstriction (Davis 1994; Donato 1994; Winkler 1995). Mannitol may also improve cerebral perfusion by decreasing viscosity, or by altering red blood cell rheology (Andrews 1993). As a free radical scavenger, mannitol may exert a protective effect against biochemical injury (Mizoi 1986). It was observed, however, that in middle cerebral artery strokes mannitol had an effect on the non-infarcted hemisphere (Videen 2001), and in large hemispheric infarctions mannitol use did not alter midline tissue shifts (Manno 1999).

Mannitol is reported to decrease cerebral oedema, infarct size and neurological deficit in several experimental models of ischaemic stroke (Karibe 1995; Kobayashi 1994; Luvisotto 1996; Paczynski 1997; Suzuki 1980), although mostly when administered within six hours after stroke onset. The results of some animal studies do not prove the beneficial effects of mannitol in rodent (Slivka 1990) or monkey (Pena 1982) models of ischaemic stroke. The worsening of cerebral oedema by multiple dose mannitol was also reported in cats (Kaufmann 1992).

Mannitol has been used in human ischaemic brain damage for over 40 years (Brient 1965). Cerebral oedema in humans is regularly treated with mannitol, which is known to decrease ICP in several diseases (James 1977) and was found to decrease case fatality in cerebral oedema due to hepatic failure (Canalese 1982). In one study of middle cerebral artery territory stroke, treatment modalities for raised ICP, including osmotherapy, were initially effective, but ICP control could only be sustained in a minority of patients (Schwab 1996). Although mannitol decreases elevated intracranial pressure after stroke (Schwarz 1998) and results in increased cerebral perfusion pressure and brain oxygenation in large hemispheric strokes (Steiner 2001), its overall effect on stroke outcome is unclear. A harmful effect of a single very large dose was assumed although not found in complete middle cerebral artery infarcts in humans (Manno 1999). In an observational study of 800 patients with acute stroke we could not find any benefit of mannitol use, in fact, the odds for survival was lower in mannitol-treated patients especially in those with ICH (Bereczki 2003). Early highdose mannitol treatment, on the other hand, was reported to result in improved clinical outcome by two randomised trials in traumatic cerebral haemorrhages (Cruz 2002; Cruz 2004).

The most common complications of mannitol therapy are fluid and electrolyte imbalances, cardiopulmonary oedema and rebound cerebral oedema (Davis 1994; Troupp 1971). Mannitol might cause kidney failure (Oken 1994; Rabetoy 1993; Weaver 1987) in therapeutic doses, and hypersensitivity reactions may also occur (McNeill 1985).

Mannitol is widely used in acute stroke all over the world. Although there are several reports of trials that were unable to establish reliably any beneficial effect of mannitol in ischaemic or haemorrhagic strokes in humans (Candelise 1974; Candelise 1975; Gigliuto 1991; Santambrogio 1978), the guidelines of the American Heart Association (Adams 2003; Broderick 1999) as well as the guidelines of the European Stroke Initiative (EUSI 2003) currently recommend the use of mannitol in certain clinical conditions in selected cases of acute stroke. Almost $70 \%$ of physicians in China, and the majority of physicians in India use mannitol or glycerol routinely in acute stroke (Chen 1997; Kalita 2004b). Although treatment with osmotic diuretics seems logical from a physiological point of view, and mannitol has some effect on the brain in ischaemic stroke (Onar 1997; Treib 1998), it is presently not clear whether the routine use of mannitol results in increased survival and decreased dependency in patients with ischaemic stroke or non-traumatic $\mathrm{ICH}$.

\section{O B JECTIVES}

To test whether treatment with mannitol reduces short and longterm case fatality and dependency following ischaemic stroke or $\mathrm{ICH}$.

\section{METHODS}

\section{Criteria for considering studies for this review}

\section{Types of studies}

Truly randomised unconfounded clinical trials comparing the effect of mannitol with placebo or open control in patients with 
acute ischaemic stroke or non-traumatic ICH. Mannitol alone compared with standard therapy was considered confounded, whereas mannitol added to standard therapy compared with standard therapy was acceptable.

\section{Types of participants}

Patients within two weeks of onset of ischaemic stroke or $\mathrm{ICH}$. We planned to stratify trials as 'acute' (within 48 hours of stroke onset) and 'subacute' (after 48 hours of stroke onset).

\section{Types of interventions}

We included trials of mannitol administered by intravenous, oral or rectal treatment schedules. We planned to stratify the analysis by treatment route.

\section{Types of outcome measures}

We planned to extract information on the following outcomes.

\section{Primary outcome measure}

The proportion of patients dead or dependent in activities of daily living at the end of the scheduled follow-up period. Since it is likely that a number of outcome scales were used, we planned to extract data using the reported results to estimate the number of patients dead or dependent in activities of daily living. The following limits would be applied: Rankin score of 3 or more, Barthel index of 18 out of 20 or less, or 85 out of 100 or less. If other subscores of physical dependency from other outcome measures which allow the estimation of the number of patients dead or dependent at final follow up are reported then we would also extract these data. If the same continuous outcome scales are used in the studies, we would also analyse these data.

\section{Secondary outcome measures}

- Deaths from all causes within the scheduled treatment period

- Deaths from all causes at the end of the scheduled follow-up period

- Length of hospital stay

- Quality of life at final follow up

- Adverse events

Regarding safety parameters, we planned to determine the rate of kidney failure, pulmonary oedema, pulmonary embolism, and the frequency of other fatal and non-fatal adverse events in each treatment group.

\section{Search methods for identification of studies}

\section{See: 'Specialized register' section in Cochrane Stroke Group}

We searched the Cochrane Stroke Group Trials Register, which was last searched by the Review Group Co-ordinator in December 2006. In addition, one of the authors (ML) searched for studies published in Chinese in the Chinese Stroke Trials Register (last searched November 2006), and in the China Biological Medicine Database (last searched December 2006). For the previous version of this review we searched MEDLINE (PubMed) (1966 to 1999) using the following search strategy.

1. (stroke or cerebrovascular or cerebral or brain).tw

2. (mannitol or mannit).tw

3. 1 and 2
We repeated this search, limited to human studies, in January 2007.

To extend our search of non-English language resources, another author (GFP) searched the following Spanish and Portuguese resources.

(1) LILACS: Latin American and Caribbean Health Sciences Literature database (LILACS 1997) (1982 to December 2006, last searched January 2007) with the keyword MANITOL and its variations in the Portuguese and Spanish languages using the strategy suggested by Castro et al (Castro 1997).

(2) The database of Masters and PhD degree theses at Sao Paulo University (BIREME/PAHO-WHO: Biblioteca Regional de Medicina/Panamerican Health Organization of the World Health Organization). This database contains details of all Brazilian theses in the field of medicine, and was last searched in January 2007.

(3) Proceedings of medical conferences on neurology and neurosurgery held in Brazil from 1965 to 2006; the last search was done in September 2006.

We also checked the reference lists of published trials to identify further relevant reports, and contacted trialists in an effort to obtain missing data from the published trials.

\section{Data collection and analysis}

\section{Methods used to select trials for inclusion}

At least two of the four review authors independently judged each identified trial to determine if it should be included in the review. For studies reported in non-English languages, one of the review authors had to know the language and the other review author made their decision based on the data extracted. For trials reported in languages not familiar to the review authors, we planned to arrange consultations to obtain a reliable translation. Such consultations were held for trial reports in Chinese. We resolved disagreements by discussion among the review authors. Before data analysis, all review authors agreed on each trial to be included.

\section{Criteria and methods used to assess the methodological quality of the included trials}

We used a structured data collection form. We evaluated the trials for methodological quality, including the method of randomisation and blinding, the concealment of randomisation, the balance in baseline prognostic factors between treatment and control groups, whether computerised tomography (CT) scanning was performed, patient follow up, and whether an intention-to-treat analysis was performed.

\section{Methods used to collect data from the included trials}

After reaching an agreement on which trials to include, two of the review authors (DB and IF) independently extracted data from the trials and performed the data analysis. Agreement of data extraction was checked by comparing the two results.

\section{Methods used to synthesise the data}

We performed data synthesis and analysis using the Cochrane Review Manager software, RevMan 4.2. We planned to use the Isquared test to assess heterogeneity between the studies. We used the Peto odds ratio for calculating relative treatment effects.

We planned to include all trials in the primary analysis, irrespective of whether the trials primarily intended to include patients with 
only ischaemic stroke or only haemorrhagic stroke. We planned separate subgroup analyses on outcome in patients with confirmed ischaemic stroke, and in patients with ICH confirmed by CT scan or CSF examination. As mannitol might be more effective in patients with more severe brain oedema, we planned to perform a subgroup analysis for those patients who had a decreased level of consciousness. We planned a further subgroup analysis for studies with intravenous administration of mannitol. Trials would be analysed separately if a dose of at least $1 \mathrm{~g} / \mathrm{kg}$ of mannitol was given as it was found that administration of $1 \mathrm{~g} / \mathrm{kg} / \mathrm{dose}$, or higher, consistently reduced ICP from control values, but dosages below $1 \mathrm{~g} / \mathrm{kg} /$ dose did not always reduce ICP (James 1980). We planned a separate analysis of studies where the total daily dose was divided into three or more doses as the oedema-reducing effect of mannitol lasts for a few hours. We planned a further analysis of studies where mannitol was given for longer than seven days as oedema around the ischaemic or haemorrhagic region might persist for longer periods of time. We also planned to do a sensitivity analysis to compare the overall results when all trials were included with the results when the analysis is restricted to trials in which patients had a CT scan.

\section{RES U L T S}

\section{Description of studies}

The searches resulted in sixteen possibly randomised controlled trials for possible inclusion. Eight of these studies were published in Chinese language journals (Jiang 1993; Kong 1996; Shi 2000; Wu 1993; Xie 1992; Xie 1996; Zhao 1987; Zhen 1996) but all of them turned out to be either not truly randomised or confounded trials, therefore these trials were excluded. In the studies by Freeman et al (Freeman 1978) and Hooshmand et al (Hooshmand 1972) dexamethasone was co-administered with mannitol, therefore no clear conclusion could be made for mannitol from these trials and they were excluded. The trial of Battison et al (Battison 2005) as well as the trials of Cruz et al (Cruz 2002; Cruz 2004) studied patients with traumatic lesions and did not include patients with ischaemic stroke or spontaneous intracerebral haemorrhages, therefore these trials were also excluded. Three studies fulfilled the inclusion criteria for this review. The study by Santambrogio et al randomised 300 patients to one control and three treatment groups: a mixture of ergot alkaloids, dexamethasone or mannitol (Santambrogio 1978). Mannitol was administered intravenously once a day in a dose of 0.8 to $0.9 \mathrm{~g} / \mathrm{kg}$ for 10 days. Data are reported on 166 patients, 41 belonged to the control group and 36 to the mannitol group. The reported outcome of the only included study of ischaemic stroke was the change in clinical condition categorised as improved, unchanged, or worsened. Kalita et al (Kalita 2004a) evaluated the effect of a single dose of intravenous mannitol (100 $\mathrm{ml} 20 \%$ solution) on regional cerebral blood flow in patients with CT-proven ICH. Originally 29 patients were randomised to the study (15 mannitol and 14 controls) within six days of stroke onset, but data are reported for 12 mannitol-treated patients and nine controls. Changes in Glasgow coma scale score and a single-photon emission computed tomography (SPECT) asymmetry index were the endpoints. Case fatality was also recorded at one month. To achieve intention-to-treat analysis, we requested clinical outcome data for the eight missing cases from the authors. The trial of Misra et al (Misra 2005) included 128 patients with CT-proven ICH, and the reported outcomes are case fatality at one month and functional disability at three months. In this trial $20 \mathrm{~g}(100 \mathrm{ml} 20 \%)$ of mannitol was given every four hours for five days.

\section{Risk of bias in included studies}

In the trial of Santambrogio et al (Santambrogio 1978) $45 \%$ of the patients were excluded from the data analysis. Based on clinical criteria, those who were assumed to have cerebral haemorrhage, cerebral embolism, or transient ischaemic attack, were excluded. Of the 300 patients, 241 had presumed ischaemic stroke, but only 166 were included in the data analysis, that is in addition to those who were excluded due to presumed haemorrhagic strokes, more than $30 \%$ of patients with presumed ischaemic events were not included in the data analysis. The number of patients randomised initially to the different groups but not included in data analysis is not reported and no intention-to-treat analysis was performed. The method of randomisation was not reported and no information about the concealment of allocation and blinding of outcome evaluation was available. CT was either not performed or the results not reported in the study. As clinical and CSF examinations are not reliable methods to exclude cerebral haemorrhage, some of those who were considered to have ischaemic strokes might have had haemorrhagic stroke. Follow up was not performed after 10 days. Case fatality and the proportion of those who were dependent were not reported and data were not available from the investigators. There was no mention about adverse events.

Kalita et al (Kalita 2004a) randomised 29 patients within six days of stroke onset using a randomisation table. There is no information about the concealment of allocation and blinding of outcome evaluation. CT was performed in all patients to prove $\mathrm{ICH}$. Although the primary endpoints of the study were the acute change in Glasgow coma scale score and the reduction in asymmetry in the SPECT images, case fatality at one month after treatment of a single infusion was also reported. Data for 21 out of 29 patients are presented: eight patients (three in the mannitol group and five in the control group) were excluded from analysis due to the poor quality of the SPECT images. There was no mention about adverse events. Survival and disability data for these eight patients were requested from the investigators but no answer was received.

Misra et al (Misra 2005) randomised 128 patients within six days of $\mathrm{ICH}$ onset using random table numbers. Randomisation was stratified according to haematoma size (small, medium, large) on the CT images. CT was performed before randomisation in all patients. Randomisation and outcome evaluations were performed by independent investigators. The primary endpoint was case fatality at one month. Disability (Barthel index) at three months and case fatality at one week is also reported. Functional disability was poor if the Barthel index score was below 12 of 20, partial if the score was between 12 and 19 . The level of dependency was not reported. Sample size estimation was done assuming $20 \%$ reduction in case fatality in the treated group. 164 patients were screened and 128 of them were randomised ( 65 to the mannitol group and 63 to the control group). There were no patients lost to follow up.

\section{Effects of interventions}

\section{Comparison 01.01: Death or disability}

In the only trial of ischaemic stroke (Santambrogio 1978) the reported outcome was the change in clinical condition and no data on death and dependency was published or was available from the investigators. One death occurred in the small trial of $\mathrm{ICH}$ 
(Kalita 2004a), but due to lack of data on dependency, the primary outcome measure could not be evaluated in this trial. The primary outcome measure of this review could be approximated only for one trial of ICH (Misra 2005). In this trial poor outcome (death or severe disability) occurred in 39 mannitol-treated patients and in 34 controls. Of those with large haemorrhages all patients had poor outcome in the mannitol group (23 out of 23) as well as in the control group (20 out of 20 ). In medium-sized haematomas poor outcome occurred in 14 of the 23 participants in the mannitol group, and 13 of the 21 participants in the control group. Of the 96 survivors, outcome was poor in 23 out of 49 mannitol-treated participants, and 18 out of 47 controls. As data on dependency was not reported, instead of the planned primary outcome measure of death and dependency, we could only analyse poor outcome as death and severe disability, and considered those who scored less than 12 on the Barthel index to be severely disabled. There was no statistically significant difference between the treatment groups.

\section{Comparison 01.02: Case fatality}

In the only trial of ischaemic stroke (Santambrogio 1978) no data on death was published or available from the investigators. At one month one patient died in the mannitol group and none among the controls in the small trial of ICH (Kalita 2004a). In the other trial of $\mathrm{ICH}$, in the first week of treatment 10 patients died, whereas by one month 16 patients died in each group ( 65 mannitol and 63 control), with no difference between the mannitol and the control groups (Misra 2005).

\section{Comparisons 01.03 and 01.04: Clinical condition worsening/ not improving}

Change in clinical condition is not included among the predefined secondary outcome measures of this review. However, as very few data exist for mannitol from randomised trials, and two of the three trials reported this outcome, it might be interesting to look at these numbers as well. The reported outcome of the only study of ischaemic stroke (Santambrogio 1978) was the change in clinical condition categorised as improved, unchanged, or worsened. Fourteen of 41 controls (34\%) and 12 of 36 mannitoltreated patients $(33 \%)$ improved, whereas the number of those whose condition worsened was 18 of $41(44 \%)$ and 16 of 36 $(44 \%)$ in the control and mannitol-treated groups, respectively, with no difference between groups. In the small study of $\mathrm{ICH}$, the Glasgow Coma Scale score improved in six out of 12 mannitoltreated patients, and seven out of nine control patients (Kalita 2004a). Worsening was recorded in two out of 12 mannitol-treated patients and none among the nine controls. The proportion of those with worsening or not improving clinical condition did not differ between groups.

\section{Adverse events, length of hospital stay, quality of life}

No serious adverse events were reported, and no data on hospital stay and on quality of life were available. In the Misra trial, two of the mannitol-treated patients and six controls had hyponatraemia (Misra 2005).

There were too few studies to assess heterogeneity and to perform the preplanned sensitivity and subgroup analyses. Using the Peto odds ratios method, neither beneficial nor harmful effects of mannitol could be found. Based on the limited data available, short (one week) and long-term (one month) case fatality, and the proportion of dead or severely disabled patients at the end of the follow up were not significantly different in mannitol-treated patients and in controls. Similarly, the proportion of those who worsened and those who did not improve were also not statistically different between mannitol-treated patients and controls. Mannitol did not prove to have beneficial or harmful effect if the analysis was restricted to large or medium-sized haematomas. Although no statistically significant differences were found between the mannitol-treated and the control groups, the confidence intervals for the treatment effect estimates were wide and included both clinically significant benefits and clinically significant harms as possibilities.

\section{DISCUSSION}

Despite the facts that mannitol has been widely used to decrease raised intracranial pressure (Rabinstein 2006; Schierhout 1998), and both ischaemic strokes and ICHs are associated with some cerebral oedema, very few randomised trials have been performed to study the effects of mannitol in acute stroke. Of the 16 trials found by the searches only three were unconfounded, truly randomised trials in acute ischaemic stroke or non-traumatic ICH. In the only one unconfounded randomised trial of mannitol in acute ischaemic stroke (Santambrogio 1978) the method of randomisation was not stated, information on concealment of randomisation was not available, CT was not performed, no intention-to-treat analysis was performed, the number of included patients was small, the follow-up period was very short, and no data could be obtained for case fatality and dependency from the investigators. In the two trials of ICH (Kalita 2004a; Misra 2005), case fatality, and the proportion of severely disabled patients at the end of the follow up, and the proportion of those with worsening or not improving condition did not differ significantly between mannitol-treated patients and controls. All three trials used mannitol in a dose lower than $1 \mathrm{~g} / \mathrm{kg} /$ dose, the dosage below which mannitol did not always reduce ICP (James 1980). Based on these three small trials there is currently not enough evidence to decide whether the routine use of mannitol in acute stroke would result in any beneficial or harmful effect. Therefore the routine use of mannitol in all patients with acute stroke is not supported by any evidence from the existing randomised clinical trials.

\section{AUTHORS' CONCLUSIONS}

\section{Implications for practice}

Although the beneficial effect of mannitol in acute stroke can not be excluded, and the use of mannitol in certain clinical conditions in selected cases of acute stroke might be appropriate (for example, in those with decreased level of consciousness), the routine use of mannitol in all patients with acute stroke cannot be recommended at present.

\section{Implications for research}

The clinical efficacy of mannitol in acute stroke has not yet been properly evaluated. Based on some animal experiments and clinical observations mannitol has effects that might be beneficial in acute stroke. To prove this hypothesis placebo-controlled, unconfounded, properly randomised clinical studies have to be designed and performed. In these studies the registration of early and late case fatality and of valid and reliable measures of dependency and disability are recommended. Brain CT should be part of the study protocol, long-term follow up (for example, 
three and six months) should be mandatory, and intention-to-treat analysis should be performed.

\section{ACKNOWLEDGEMENTS}

The review authors thank Professor Peter Sandercock, and also Professor Fernando Porro regarding unpublished information about one of the trials included in this review (Santambrogio 1978). We are grateful to Hazel Fraser and Brenda Thomas for searching the Cochrane Stroke Group Trials Register, and to Dr You Hong for assessing the design of three Chinese trials (Jiang 1993; Shi 2000; Zhen 1996). 


\section{R E F E R E N C E S}

\section{References to studies included in this review}

Kalita 2004a \{published data only\}

Kalita J, Misra UK, Ranjan P, Pradhan PK, Das BK. Effect of mannitol on regional cerebral blood flow in patients with intracerebral hemorrhage. Journal of the Neurological Sciences 2004;224(1-2):19-22.

\section{Misra 2005 \{published data only\}}

Misra UK, Kalita J, Ranjan P, Mandal SK. Mannitol in intracerebral hemorrhage: a randomized controlled study. Journal of the Neurological Sciences 2005;234(1-2):41-5.

\section{Santambrogio 1978 \{published data only\}}

Santambrogio S, Martinotti R, Sardella F, Porro F, Randazzo A. Is there a real treatment for stroke? Clinical and statistical comparison of different treatments in 300 patients. Stroke 1978;9:130-2

\section{References to studies excluded from this review}

Battison 2005 \{published data only\}

Battison C, Andrews PJ, Graham C, Petty T. Randomized, controlled trial on the effect of a $20 \%$ mannitol solution and a $7.5 \%$ saline $/ 6 \%$ dextran solution on increased intracranial pressure after brain injury. Critical Care Medicine 2005;33(1):196-202.

\section{Cruz 2002 \{published data only\}}

Cruz J, Minoja G, Okuchi K. Major clinical and physiological benefits of early high doses of mannitol for intraparenchymal temporal lobe hemorrhages with abnormal pupillary widening: a randomized trial. Neurosurgery 2002;51(3):628-37.

\section{Cruz 2004 \{published data only\}}

Cruz J, Minoja G, Okuchi K, Facco E. Successful use of the new high-dose mannitol treatment in patients with Glasgow Coma Scale scores of 3 and bilateral abnormal pupillary widening: a randomized trial. Journal of Neurosurgery 2004;100(3):376-83.

\section{Freeman 1978 \{published data only\}}

Freeman J, Tappin J, Karat ABA, Meecham J. Dexamethasone in acute stroke. BMJ 1978;2:1500.

\section{Hooshmand 1972 \{published data only\}}

Hooshmand H, Quinn JC, Houff SA. Cerebrospinal fluid pressure changes with chemotherapy for intracerebral hemorrhage. Neurology 1972;22(1):56-61.

\section{Jiang 1993 \{published data only\}}

Jiang DB, Han ZY, Wang DQ. Insulin and mannitol in treatment of acute cerebral infarction. Chinese Journal of Neurology \& Psychiatry 1993;26:84-7.

\section{Kong 1996 \{published data only\}}

Kong YN. Free radical scavanger in the treatment of cerebral infarction (40 cases). Journal of Clinical Neurology 1996;9:174-5.
Shi 2000 \{published data only\}

Shi Y, Kong X. Influence of mannitol on early enlargement of hematoma in hypertensive cerebral hemorrhage. Chinese Medical Journal 2000;80(11):849-51.

Wu 1993 \{published data only\}

Wu SH. Mannitol in the treatment of acute cerebral infarction (analysis of 50 cases). Journal of Stroke and Neurological Diseases 1993;10(3):177-8.

Xie 1992 \{published data only\}

Xie P, Sen X, Hu Y. Low dose mannitol in the treatment of acute stroke. Journal of Clinical Neurology 1992;5(1):52-61.

\section{Xie 1996 \{published data only\}}

Xie P, Sen X. A prospective study of small amount of mannitol and insulin in the treatment of acute cerebral infarction. Journal of Brain and Neurological Diseases 1996;4:21-3.

Zhao 1987 \{published data only\}

Zhao PX. Clinical study on the effect of $20 \%$ mannitol in treating cerebral thrombosis. Chung Hua Shen Ching Ching Shen Ko Tsa Chih 1987;20(3):169-72.

\section{Zhen 1996 \{published data only\}}

Zhen JG. Clinical effectiveness of acupuncture using 'Xian-NauKai-Xiau' technique for acute cerebral haemorrhage. Tianjing Traditional Medical College Bulletin 1996;4:21-3.

\section{Additional references}

\section{Adams 1996}

Adams HP, Brott TG, Furlan AJ, Gomez CR, Grotta J, Helgason CM, et al. Guidelines for thrombolytic therapy for acute stroke: a supplement to the guidelines for the management of patients with acute ischemic stroke. A statement for healthcare professionals from a special writing group of the Stroke Council, American Heart Association. Circulation 1996;94:1167-74.

\section{Adams 2003}

Adams HP Jr, Adams RJ, Brott T, del Zoppo GJ, Furlan A Goldstein LB, et al. Guidelines for the early management of patients with ischemic stroke: a scientific statement from the Stroke Council of the American Stroke Association. Stroke 2003;34(4):1056-83.

\section{Andrews 1993}

Andrews RJ, Bringas JR, Muto RP. Effects of mannitol on cerebral blood flow, blood pressure, blood viscosity, hematocrit, sodium, and potassium. Surgical Neurology 1993;39:218-22.

\section{Bereczki 2003}

Bereczki D, Mihalka L, Szatmari S, Fekete K, Di Cesar D, Fulesdi B, et al. Mannitol use in acute stroke: case fatality at 30 days and 1 year. Stroke 2003;34(7):1730-5. 


\section{Brient 1965}

Brient BW, Zimmerman JM, King TC. The effect of prolonged hypothermia and mannitol infusion upon the neurologic sequelae of total cerebral ischemia. Surgical Forum 1965;16:407-8.

\section{Broderick 1999}

Broderick JP, Adams HP Jr, Barsan W, Feinberg W, Feldmann E, Grotta J, et al. Guidelines for the management of spontaneous intracerebral hemorrhage: a statement for healthcare professionals from a special writing group of the Stroke Council, American Heart Association. Stroke 1999;30(4):905-15.

\section{Canalese 1982}

Canalese J, Gimson AE, Davis C, Mellon PJ, Davis M, Williams R. Controlled trial of dexamethasone and mannitol for the cerebral oedema of fulminant hepatic failure. Gut 1982;23:625-9.

\section{Candelise 1974}

Candelise L, Colombo A, Spinnler H. Anti-oedema treatment of completed stroke. Lancet 1974;861:806.

\section{Candelise 1975}

Candelise L, Colombo A, Spinnler H. Therapy against brain swelling in stroke patients. A retrospective clinical study on 227 patients. Stroke 1975;6:353-6.

\section{CAST 1997}

CAST (Chinese Acute Stroke Trial) Collaborative Group. CAST: randomised placebo-controlled trial of early aspirin use in 20,000 patients with acute ischaemic stroke. Lancet 1997;349:1641-9.

\section{Castro 1997}

Castro AA, Clark OAC, Atallah AN. Optimal search strategy for clinical trials in the Latin American Caribbean Health Science Literature Database (LILACS). São Paulo Medical Journal (Revista Paulista de Medicina) 1997;115:1423-6.

\section{Chen 1997}

Chen ZM, Sandercock P, Xie JX, Peto R, Collins R, Liu LS. Hospital management of acute ischaemic stroke in China. Journal of Stroke and Cerebrovascular Diseases 1997;6:361-7.

\section{Davis 1994}

Davis M, Lucatorto M. Mannitol revisited. Journal of Neuroscience Nursing 1994;26:170-4.

\section{Donato 1994}

Donato T, Shapira Y, Artru A, Powers K. Effect of mannitol on cerebrospinal fluid dynamics and brain tissue edema. Anesthesia and Analgesia 1994;78:58-66.

\section{Ebisu 1997}

Ebisu T, Tanaka C, Umeda M, Kitamura M, Fukunaga M, Aoki I, et al. Hemorrhagic and nonhemorrhagic stroke: diagnosis with diffusion-weighted and T2-weighted echo-planar MR imaging. Radiology 1997;203:823-8.

\section{EUSI 2003}

Hacke W, Kaste M, Bogousslavsky J, Brainin M, Chamorro A, Lees K, et al. European Stroke Initiative recommendations for stroke management: update 2003. Cerebrovascular Diseases 2003;16(4):311-37.

\section{Gigliuto 1991}

Gigliuto CM, Stone KE, Algus M. The use of mannitol in intracerebral bleeds in the medical ICU. New Jersey Medicine 1991;88:48-51.

\section{Haass 1987}

Haass A, Kloss R, Brenner M, Hamann G, Harms M, Schimrigk K. Intracranial pressure-controlled treatment of brain edema with glycerin and sorbitol in intracerebral hemorrhage. Nervenarzt 1987;58:22-9.

\section{IST 1997}

International Stroke Trial Collaborative Group. The International Stroke Trial (IST): a randomised trial of aspirin, subcutaneous heparin, both, or neither among 19435 patients with acute ischaemic stroke. Lancet 1997;349:1569-81.

\section{James 1977}

James HE, Langfitt TW, Kumar VS, Ghostine SY. Treatment of intracranial hypertension. Analysis of 105 consecutive, continuous recordings of intracranial pressure. Acta Neurochirurgica 1977;36:189-200.

\section{James 1980}

James HE. Methodology for the control of intracranial pressure with hypertonic mannitol. Acta Neurochirurgica 1980;51:161-72.

\section{Kalita 2004b}

Kalita J, Misra UK, Ranjan P. Prescribing pattern of antiedema therapy in stroke by neurologists and general physicians. Neurology India 2004;52(2):191-3.

\section{Karibe 1995}

Karibe H, Zarow GJ, Weinstein PR. Use of mild intra-ischemic hypothermia versus mannitol to reduce infarct size after temporary middle cerebral artery occlusion in rats. Journal of Neurosurgery 1995;83:93-8.

\section{Katzman 1977}

Katzman R, Clasen R, Klatzo I, Meyer JS, Pappius HM, Waltz AG. Report of Joint Committee for Stroke Resources: IV. Brain edema in stroke. Stroke 1977;8:512-40.

\section{Kaufmann 1992}

Kaufmann AM, Cardoso ER. Aggravation of vasogenic cerebral edema by multiple dose mannitol. Journal of Neurosurgery 1992;77:584-9.

\section{Kobayashi 1994}

Kobayashi H, Ide H, Kodera T, Handa Y, Kabuto M, Kubota T, et al. Effect of mannitol on focal cerebral ischemia evaluated by magnetic resonance imaging. Acta Neurochirurgica. Supplementum 1994;60:228-30. 


\section{LILACS 1997 [Computer program]}

BIREME-OPS/OMS. Literatura Latinoamericana y del Caribe en Ciencias de la Salud (LILACS). Version 29a. BIREME-OPS/OMS, September 1997.

\section{Luvisotto 1996}

Luvisotto TL, Auer RN, Sutherland GR. The effect of mannitol on experimental cerebral ischemia, revisited. Neurosurgery 1996;38:131-8

\section{Manno 1999}

Manno EM, Adams RE, Derdeyn CP, Powers WJ, Diringer MN. The effects of mannitol on cerebral edema after large hemispheric cerebral infarct. Neurology 1999;52(3):583-7.

\section{Mayer 2005}

Mayer SA, Brun NC, Begtrup K, Broderick J, Davis S, Diringer MN, et al. Recombinant activated factor VII for acute intracerebral hemorrhage. New England Journal of Medicine 2005;352:777-85.

\section{McNeill 1985}

McNeill IY. Hypersensitivity reaction to mannitol. Drug Intelligence \& Clinical Pharmacy 1985;19:552-3.

\section{Mendelow 2005}

Mendelow AD, Gregson BA, Fernandes HM, Murray GD, Teasdale GM, Hope DT, et al. Early surgery versus initial conservative treatment in patients with spontaneous supratentorial intracerebral haematomas in the International Surgical Trial in Intracerebral Haemorrhage (STICH): a randomised trial. Lancet 2005;365:387-97.

\section{Mizoi 1986}

Mizoi K, Suzuki J, Imaizumi S, Yoshimoto T. Development of new cerebral protective agents: the free radical scavengers. Neurological Research 1986;8:75-80.

\section{Oken 1994}

Oken DE. Renal and extrarenal considerations in high-dose mannitol therapy. Renal Failure 1994;16:147-59.

\section{Onar 1997}

Onar M, Arik Z. The evaluation of mannitol therapy in acute ischemic stroke patients by serial somatosensory evoked potentias. Electromyography and Clinical Neurophysiology 1997;37:213-8.

\section{Paczynski 1997}

Paczynski RP, He YY, Diringer MN, Hsu CY. Multiple-dose mannitol reduces brain water content in a rat model of cortical infarction. Stroke 1997;28:1437-43.

\section{Pena 1982}

Pena H, Gaines C, Suess D, Crowell RM, Waggener JD, DeGirolami U. Effect of mannitol on experimental focal ischemia in awake monkeys. Neurosurgery 1982;11:477-81.

\section{Poungvarin 1987}

Poungvarin N, Bhoopat W, Viriyavejakul A, Rodprasert P, Buranasiri $\mathrm{P}$, Sukondhabhant $\mathrm{S}$, et al. Effects of dexamethasone in primary supratentorial intracerebral hemorrhage. New England Journal of Medicine 1987;316:1229-33.

\section{Prasad 1998}

Prasad K, Shrivastava A. Surgical treatment in patients with primary supratentorial intracerebral haemorrhage. Cochrane Database of Systematic Reviews 1998, Issue 2. [Art. No.: CD000200. DOI: 10.1002/14651858.CD000200]

\section{Qizilbash 2002}

Qizilbash N, Lewington SL, Lopez-Arrieta JM. Corticosteroids for acute ischaemic stroke. Cochrane Database of Systematic Reviews 2002, Issue 3. [Art. No.: CD000064. DOI: 10.1002/14651858.CD000064]

\section{Rabetoy 1993}

Rabetoy GM, Fredericks MR, Hostettler CF. Where the kidney is concerned, how much mannitol is too much?. Annals of Pharmacotherapy 1993;27:25-8.

\section{Rabinstein 2006}

Rabinstein AA. Treatment of cerebral edema. Neurologist 2006;12:59-73.

\section{Reyes 1981}

de los Reyes RA, Ausman JI, Diaz FG. Agents for cerebral edema. Clinical Neurosurgery 1981;28:98-107.

\section{Righetti 2004}

Righetti E, Celani MG, Cantisani T, Sterzi R, Boysen G, Ricci S. Glycerol for acute stroke. Cochrane Database of Systematic Reviews 2004, Issue 2. [Art. No.: CD000096. DOI: 10.1002/14651858.CD000096]

\section{Schierhout 1998}

Schierhout G, Roberts I. Mannitol in acute traumatic brain injury. Cochrane Database of Systematic Reviews 1998, Issue 1. [Art. No.: CD001049. DOI: 10.1002/14651858.CD0010]

\section{Schlaug 1997}

Schlaug G, Siewert B, Benfield A, Edelman RR, Warach S. Time course of the apparent diffusion coefficient (ADC) abnormality in human stroke. Neurology 1997;49:113-9.

\section{Schwab 1996}

Schwab S, Schellinger P, Aschoff A, Albert F, Spranger M, Hacke W. Epidural cerebrospinal fluid pressure measurement and therapy of intracranial hypertension in 'malignant' middle cerebral artery infarct. Nervenarzt 1996;67:659-66.

\section{Schwarz 1998}

Schwarz S, Schwab S, Bertram M, Aschoff A, Hacke W. Effects of hypertonic saline hydroxyethyl starch solution and mannitol in patients with increased intracranial pressure after stroke. Stroke 1998;29(8):1550-5.

\section{Slivka 1990}

Slivka A, Silbersweig D, Pulsinelli W. Carnitine treatment for stroke in rats. Stroke 1990;21:808-11. 


\section{Steiner 2001}

Steiner T, Pilz J, Schellinger P, Wirtz R, Friederichs V, Aschoff A, et al. Multimodal online monitoring in middle cerebral artery territory stroke. Stroke 2001;32(11):2500-6.

\section{Suzuki 1980}

Suzuki J, Tanaka S, Yoshimoto T. Recirculation in the acute period of cerebral infarction: brain swelling and its suppression using mannitol. Surgical Neurology 1980;14:467-72.

\section{Treib 1998}

Treib J, Becker SC, Grauer M, Haass A. Transcranial Doppler monitoring of intracranial pressure therapy with mannitol, sorbitol and glycerol in patients with acute stroke. European Neurology 1998;40(4):212-9.

\section{Troupp 1971}

Troupp H, Valtonen S, Vapalahti M. Intraventricular pressure after administration of dehydrating agents to severely braininjured patients: is there a rebound phenomenon?. Acta Neurochirurgica 1971;24:89-95.

\section{Videen 2001}

Videen TO, Zazulia AR, Manno EM, Derdeyn CP, Adams RE, Diringer MN, et al. Mannitol bolus preferentially shrinks noninfarcted brain in patients with ischemic stroke. Neurology 2001;57(11):2120-2.

\section{Warach 1995}

Warach S, Gaa J, Siewert B, Wielopolski P, Edelman RR. Acute human stroke studied by whole brain echo planar diffusionweighted magnetic resonance imaging. Annals of Neurology 1995;37:231-41.

\section{CHARACTERISTICS OF STUDIES}

Characteristics of included studies [ordered by study ID]

\section{Wardlaw 2003}

Wardlaw JM, del Zoppo G, Yamaguchi T, Berge E. Thrombolysis for acute ischaemic stroke. Cochrane Database of

Systematic Reviews 2003, Issue 3. [Art. No.: CD000213. DOI: 10.1002/14651858.CD000213]

\section{Weaver 1987}

Weaver A, Sica DA. Mannitol-induced acute renal failure. Nephron 1987;45:233-5.

\section{Winkler 1995}

Winkler SR, Munoz-Ruiz L. Mechanism of action of mannitol. Surgical Neurology 1995;43:59.

\section{Woster 1990}

Woster PS, LeBlanc KL. Management of elevated intracranial pressure. Clinical Pharmacy 1990;9:762-72.

\section{Yu 1992}

Yu YL, Kumana CR, Lauder IJ, Cheung YK, Chan FL, Kou M, et al. Treatment of acute cerebral hemorrhage with intravenous glycerol. A double-blind, placebo-controlled, randomized trial. Stroke 1992;23:967-71.

\section{References to other published versions of this review \\ Bereczki 2000}

Bereczki D, Liu M, Prado GF, Fekete I. Cochrane report: a systematic review of mannitol therapy for acute ischemic stroke and cerebral parenchymal hemorrhage. Stroke 2000;31:2719-22.

\section{Bereczki 2001}

Bereczki D, Liu M, Prado GF, Fekete I. Mannitol for acute stroke. Cochrane Database of Systematic Reviews 2001, Issue 1. [Art. No.: CD001153. DOI: 10.1002/14651858.CD001153]

Kalita 2004a

$\begin{array}{ll}\text { Methods } & \text { RCT } \\ & 29 \text { patients randomised; data for } 21 \text { are reported }\end{array}$

\begin{tabular}{ll}
\hline Participants & CT-proven ICH, within 6 days of stroke onset \\
\hline Interventions & A single iv infusion of $100 \mathrm{ml} 20 \%$ mannitol (about $0.3 \mathrm{mg} / \mathrm{kg}$ ) vs saline \\
\hline Outcomes & $\begin{array}{l}\text { Improvement of GCS } \\
\text { Reduction in SPECT asymmetry } \\
\text { Case fatality at } 1 \text { month }\end{array}$ \\
\hline Notes & $\begin{array}{l}\text { Data on case fatality for } 8 \text { missing cases may be available (missing data have been requested but not } \\
\text { yet received from co-author Dr Misra ) }\end{array}$ \\
\hline
\end{tabular}

\section{Risk of bias}


Kalita 2004a (Continued)

Allocation concealment? Unclear risk B - Unclear

Misra 2005

$\begin{array}{ll}\text { Rethods } & \text { RCT } \\ & 128 \text { patients randomised using a random number table } \\ \text { Patient assessment and randomisation done by independent investigators } \\ \text { Randomisation stratified by haematoma size }\end{array}$

Participants CT-proven ICH, within 6 days of stroke onset

\begin{tabular}{ll}
\hline Interventions & IV infusion of $100 \mathrm{ml} 20 \%$ mannitol each 4 hours for 5 days vs saline \\
\hline Outcomes & 1-month case fatality \\
& Functional disability at 3 months \\
\hline
\end{tabular}

Notes No patients lost to follow up

The number of those who were dead or severely disabled at 3 months can be calculated from data

\section{Risk of bias}

\begin{tabular}{lll}
\hline Bias & Authors' judgement & Support for judgement \\
\hline Allocation concealment? & Low risk & A - Adequate \\
\hline
\end{tabular}

Santambrogio 1978

\begin{tabular}{|c|c|c|}
\hline Methods & \multicolumn{2}{|c|}{$\begin{array}{l}\text { RCT } \\
300 \text { patients included, } 241 \text { were considered ischaemic stroke by clinical signs or CSF or both, data for } \\
\text { only } 166 \text { analysed. Of these } 166 \text { patients } 41 \text { were controls, } 36 \text { were treated with mannitol, } 41 \text { with ergot } \\
\text { alkaloids and } 48 \text { with dexamethasone in addition to standard therapy } \\
\text { CT was not performed or data not reported }\end{array}$} \\
\hline Participants & \multicolumn{2}{|c|}{$\begin{array}{l}\text { Presumed ischaemic stroke, } 2 \text { to } 24 \text { hours after stroke onset } \\
\text { Patients with TIA, presumed embolic stroke and presumed cerebral haemorrhage were dropped from } \\
\text { data analysis }\end{array}$} \\
\hline Interventions & \multicolumn{2}{|c|}{$\begin{array}{l}\text { Standard therapy for controls, standard therapy plus daily } 0.8 \text { to } 0.9 \mathrm{~g} / \mathrm{kg} \text { mannitol IV for mannitol } \\
\text { group }\end{array}$} \\
\hline Outcomes & \multicolumn{2}{|c|}{ Improvement, no change or worsening on a non-specified 30-point clinical scale in the first 10 days } \\
\hline Notes & \multicolumn{2}{|c|}{$\begin{array}{l}\text { No method of randomisation stated } \\
\text { Case fatality not given, almost } 30 \% \text { of patients were excluded from data analysis (missing data could } \\
\text { not be obtained after contacting one of the investigators, Professor Porro) }\end{array}$} \\
\hline \multicolumn{3}{|l|}{ Risk of bias } \\
\hline Bias & Authors' judgement & Support for judgement \\
\hline Allocation concealment? & Unclear risk & B - Unclear \\
\hline
\end{tabular}


CT: computerised tomography

CSF: cerebrospinal fluid

GCS: Glasgow Coma Scale

$\mathrm{ICH}$ : non-traumatic intracerebral haemorrhage

iv: intravenous

$\mathrm{RCT}$ : randomised controlled trial

TIA: transient ischemic attack

vs: versus

Characteristics of excluded studies [ordered by study ID]

\begin{tabular}{|c|c|}
\hline Study & Reason for exclusion \\
\hline Battison 2005 & $\begin{array}{l}\text { The study included patients with traumatic lesions and subarachnoid haemorrhage, and did not in- } \\
\text { clude patients with ischaemic stroke or spontaneous (non-traumatic) intraparenchymal haemor- } \\
\text { rhages }\end{array}$ \\
\hline Cruz 2002 & The study included patients with traumatic lesions \\
\hline Cruz 2004 & The study included patients with traumatic lesions \\
\hline Freeman 1978 & $\begin{array}{l}\text { Confounded study. The effect of mannitol plus dexamethasone was compared with standard thera- } \\
\text { py. The possible effect of mannitol was confounded by the simultaneous administration of dexam- } \\
\text { ethasone }\end{array}$ \\
\hline Hooshmand 1972 & $\begin{array}{l}\text { Confounded study. Dexamethasone was co-administered with mannitol. There was no pure manni- } \\
\text { tol group, therefore no clear conclusion could be made for mannitol }\end{array}$ \\
\hline Jiang 1993 & Not a RCT, all 4 groups were treated with mannitol \\
\hline Kong 1996 & $\begin{array}{l}\text { Confounded study, several other medications were co-administered in the treatment group com- } \\
\text { pared with the control group. The control group got another special treatment which was not ad- } \\
\text { ministered in the treatment group }\end{array}$ \\
\hline Shi 2000 & Not a RCT \\
\hline Wu 1993 & Confounded study. Mannitol in the treatment group, dextran in the control group \\
\hline Xie 1992 & $\begin{array}{l}\text { Not truly randomised (allocation by admission numbers). Two doses of mannitol were compared, } \\
\text { no control group }\end{array}$ \\
\hline Xie 1996 & Confounded study. Mannitol in the treatment group, dextran in the control group \\
\hline Zhao 1987 & Confounded study. Mannitol in the treatment group, dextran in the control group \\
\hline Zhen 1996 & Not a RCT \\
\hline
\end{tabular}

Standard treatment versus mannitol is considered confounded. Standard treatment versus standard treatment plus mannitol is accepted RCT: randomised controlled trial

\section{DATA AND ANALYSES}


Comparison 1. Mannitol plus standard therapy versus standard therapy

\begin{tabular}{llllll}
\hline Outcome or subgroup title & $\begin{array}{l}\text { No. of } \\
\text { studies }\end{array}$ & $\begin{array}{l}\text { No. of } \\
\text { partici- } \\
\text { pants }\end{array}$ & Statistical method & Effect size \\
\hline 1 Death or disability & 1 & 128 & Peto Odds Ratio (Peto, Fixed, 95\% Cl) & $1.28[0.64,2.56]$ \\
\hline 2 Case fatality & 2 & 149 & Peto Odds Ratio (Peto, Fixed, 95\% Cl) & $1.03[0.47,2.25]$ \\
\hline 3 Clinical condition worsening & 2 & 98 & Peto Odds Ratio (Peto, Fixed, 95\% Cl) & $1.20[0.51,2.82]$ \\
\hline 4 Clinical condition not improving & 2 & 98 & Peto Odds Ratio (Peto, Fixed, 95\% Cl) & $1.33[0.58,3.03]$ \\
\hline
\end{tabular}

Analysis 1.1. Comparison 1 Mannitol plus standard therapy versus standard therapy, Outcome 1 Death or disability.

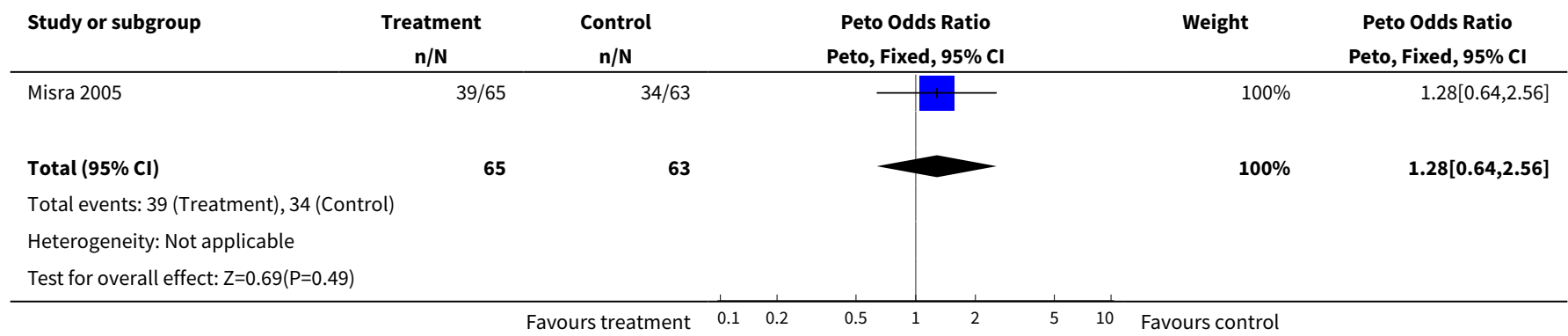

Analysis 1.2. Comparison 1 Mannitol plus standard therapy versus standard therapy, Outcome 2 Case fatality.

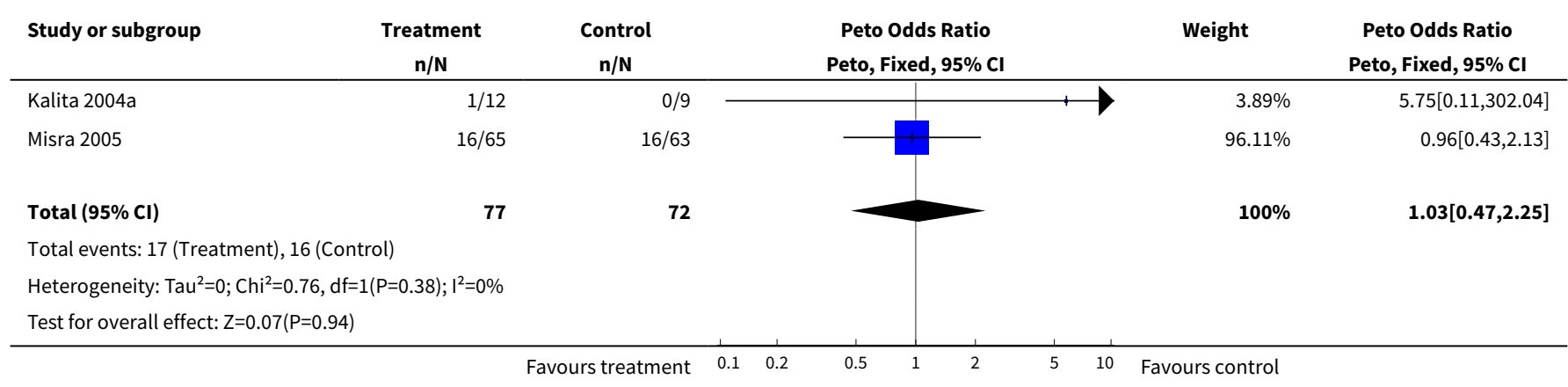

Analysis 1.3. Comparison 1 Mannitol plus standard therapy versus standard therapy, Outcome 3 Clinical condition worsening.

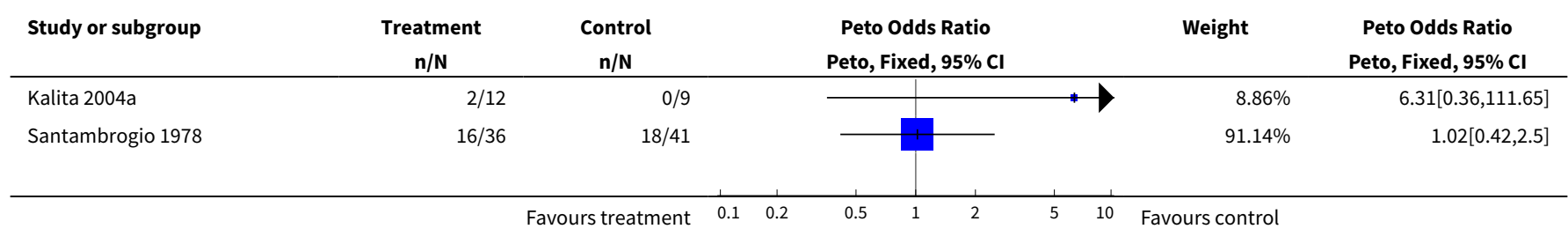




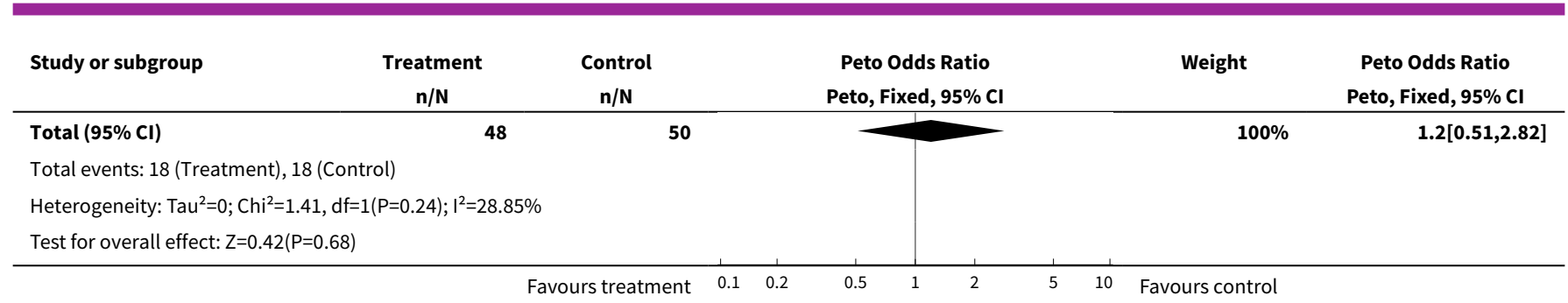

Analysis 1.4. Comparison 1 Mannitol plus standard therapy versus standard therapy, Outcome 4 Clinical condition not improving.

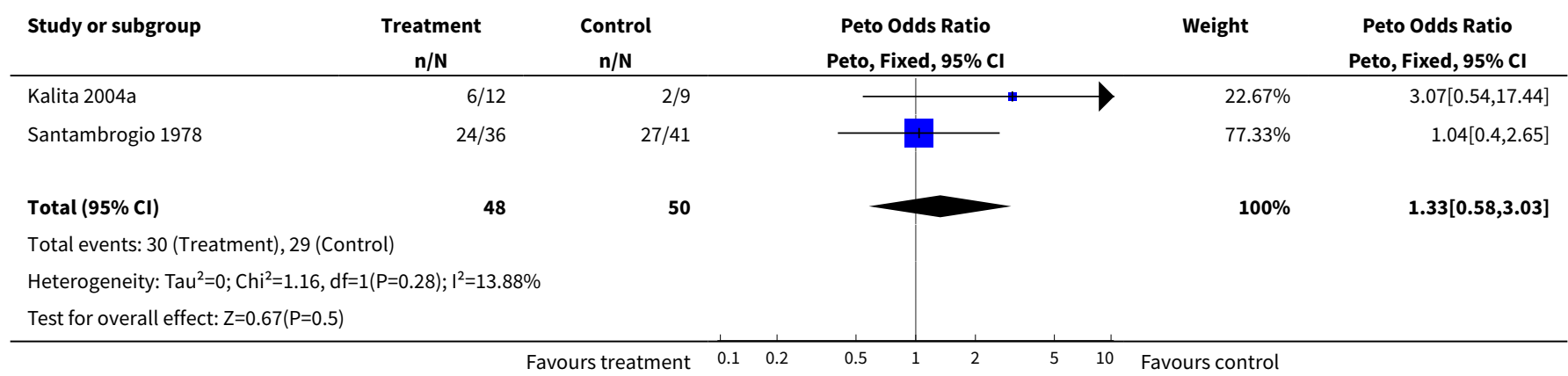

WHAT'S NEW

\begin{tabular}{lll}
\hline Date & Event & Description \\
\hline 3 September 2008 & Amended & Converted to new review format. \\
\hline
\end{tabular}

\section{HISTORY}

Protocol first published: Issue 3, 1998

Review first published: Issue 1, 2001

\begin{tabular}{lll}
\hline Date & Event & Description \\
\hline 21 January 2007 & New search has been performed & $\begin{array}{l}\text { The Background has been updated with recently published pa- } \\
\text { pers on mannitol in acute stroke. Two randomised studies have } \\
\text { been found since the previous version of the review was pub- } \\
\text { lished: both studies included patients with non-traumatic in- } \\
\text { tracerebral haemorrhage. The number of included patients was } \\
\text { small (29 and 128, respectively), and the studies did not find any } \\
\text { difference in mannitol-treated patients compared with controls } \\
\text { in short and long-term case fatality and disability. The conclu- } \\
\text { sions of the review did not change. Based on the three small ran- } \\
\text { domised trials there is no evidence to recommend the routine } \\
\text { use of mannitol in patients with acute stroke. }\end{array}$
\end{tabular}




\section{CONTRIBUTIONS OF AUTHORS}

Dr Dániel Bereczki: participated in all phases of the protocol preparation and wrote the first draft of the review with all of its obligations.

Dr Ming Liu: participated in data collection, translation and data extraction from Chinese language papers, organising retrieval of possibly relevant papers, screening papers against inclusion criteria, appraising quality of papers, abstracting data from papers, providing general advice on the protocol and review and performing previous work that was partly the foundation of the current review.

Dr Gilmar Fernandes do Prado: participated in data collection, searching the available Portuguese and Spanish language databases for possibly relevant trials, organising retrieval of possibly relevant papers, screening retrieved papers against inclusion criteria, translating and extracting data from Spanish and Portuguese language papers, appraising quality of papers, and provided general advice on the protocol and review.

Dr István Fekete: participated in data collection for the protocol, screening retrieved papers, appraising quality of papers, screening retrieved papers against the inclusion criteria, extracting data, appraising quality of papers, and provided general advice on the protocol and review.

\section{DECLARATIONS OF INTEREST}

None known

\section{SOURCES OF SUPPORT}

\section{Internal sources}

- Department of Neurology, Health Science and Medical Center, University of Debrecen, Hungary.

- Dept of Neurology, West China Hospital, Sichuan University, China.

- Department of Internal Medicine, Federal University of Sao Paulo, Brazil.

\section{External sources}

- Health Scientific Council (ETT 178/2006), Hungary.

\section{INDEX TERMS}

\section{Medical Subject Headings (MeSH)}

Acute Disease; Brain Edema [drug therapy]; Brain Ischemia [ ${ }^{*}$ drug therapy]; Cerebral Hemorrhage [ ${ }^{*}$ drug therapy]; Diuretics, Osmotic [adverse effects] [ ${ }^{\star}$ therapeutic use]; Mannitol [adverse effects] [ ${ }^{*}$ therapeutic use]; Randomized Controlled Trials as Topic

\section{MeSH check words}

Humans 